\title{
ANÁLISE DA COMBINAÇÃO DO PROCESSO DE INOVAÇÃO COM AS PRÁTICAS AMBIENTAIS
}

\author{
Dusan Schreiber ${ }^{1}$, Giselly Santos Mendes ${ }^{1}$ \\ ${ }^{1}$ FEEVALE - Universidade Feevale \\ dusan@feevale.br, giselly@ensinger.com.br
}

\begin{abstract}
Resumo
O acirramento da competição entre os agentes econômicos, notadamente nas últimas décadas, mudou as bases conceituais que determinavam as regras de atuação no mercado, exigindo a concepção de novos parâmetros para o posicionamento estratégico. Dentre eles destacou-se a inovação, como forma de migrar do paradigma de competição com base em custo, para a diferenciação, e a gestão ambiental, como resposta à deterioração do meio ambiente, em decorrência da industrialização sem controle. No entanto na medida em que a inovação estimula o crescimento do consumo, muitas vezes reduz o ciclo de vida de produtos e aumenta a geração de resíduos, ao contrário da gestão ambiental que promove uma visão oposta, em prol da mitigação do impacto ambiental. Com o objetivo geral de identificar a forma de combinar a inovação com as práticas ambientais em organizações do segmento industrial, foi realizado o estudo de caso múltiplo em três organizações, localizadas na região sul do país, por meio de abordagem qualitativa, entrevistas em profundidade e análise de narrativas. Os resultados do estudo evidenciaram que a forma adotada pelas organizações de inovar os processos em combinação com as práticas ambientais depende do posicionamento estratégico, da estrutura interna e dos recursos disponíveis para investimento.
\end{abstract}

Palavras-chave: Inovação; Práticas Ambientais; Gestão.

\section{ANÁLISE DA COMBINAÇÃO DO PROCESSO DE INOVAÇÃO COM AS PRÁTICAS AMBIENTAIS}

\begin{abstract}
The intense competition among economic agents, especially in the last decades has changed the conceptual bases that determine the rules of market action, requiring the design of new parameters for strategic positioning. Among them figure out innovation as a way to migrate from the paradigm of competition based on cost, toward differentiation, and environmental management, in response to the deterioration of the environment as a result of uncontrolled industrialization. However the extent that innovation stimulates the growth of consumption reduces the life cycle of products and increases the amount of the waste, with environmental management promoting an opposite view, in favor of the mitigation of the environmental impact. In order to investigate the alternatives of combining process innovation with environmental practices in the industrial organizations was performed multiple case study in three organizations by qualitative study, interviews and analysis of narratives. The results showed that the form adopted by organizations to innovate processes in combination with the environmental practices depends on the strategic positioning, internal structure and the resources available for investment.
\end{abstract}

Keywords: Innovation; Environmental Practices; Management. 


\section{Introdução}

A crescente complexidade, que caracteriza o mercado, cada vez mais segmentado, multifacetado e global, exige das organizações um novo conjunto de competências e capacidades. Dentre elas destacam-se a inovação e a preservação ambiental, por meio de práticas sustentáveis. Na medida em que a inovação, de produtos e de processos, visa constituir o diferencial competitivo organizacional, para deixar de competir por preços, e acelerar o ritmo de lançamentos de novos produtos; muitas vezes, acaba colocando em risco o meio ambiente, através da redução do ciclo de vida de produtos, do estímulo ao consumo exagerado, e do consequente aumento da geração de resíduos. Esta dualidade de objetivos, inovar, sem prejudicar o meio ambiente, muitas vezes antagônicos, representam um desafio relevante para as organizações, especialmente as do setor industrial.

A importância da inovação para as organizações começou a ser abordada no início do século passado por Schumpeter (1982) que retratou as restrições do modelo de competição vigente na época, fundamentado em escala de produção e preço, que tende a reduzir as margens de retorno, para todos os agentes econômicos concorrentes. Com base nesta constatação o autor construiu a vertente teórica que destaca a necessidade de inovação, por meio de "destruição criadora", quando o empreendedor desenvolve novos produtos ou concebe novos métodos de produção, abordagem mercadológica ou promove um novo arranjo de recursos disponíveis.

Ao longo das décadas seguintes diversos pesquisadores e gestores organizacionais procuraram aumentar a compreensão acerca do referido tema, contribuindo para ampliar o debate sobre os benefícios da inovação para as organizações. Como consequência do crescente interesse sobre a inovação constatou-se o aumento significativo de recursos financeiros alocados para as atividades de pesquisa e desenvolvimento, elevando o nível de competição entre os agentes no mercado e de descontrole acerca de impactos ambientais, decorrentes da redução do ciclo de vida dos produtos.

$\mathrm{O}$ acirramento da competição entre as organizações também reflete sobre o grau de exploração de matérias primas não renováveis e a geração de resíduos sólidos, líquidos e gasosos, inicialmente nos países mais desenvolvidos e, posteriormente, em decorrência do deslocamento de plantas produtoras (e poluidoras), nos países em desenvolvimento. Esta situação tornou-se particularmente crítica na década de oitenta do século passado, motivando a elaboração do relatório denominado "nosso futuro comum", pela comissão mundial do ambiente e desenvolvimento (Comissão de Brundtland), em 1987, onde foi definido o conceito de desenvolvimento sustentável. O referido conceito foi considerado basilar e contribuiu para a concepção do eixo teórico que orientou os trabalhos da comissão mundial das nações unidas para o meio ambiente e desenvolvimento. O desenvolvimento sustentável foi definido como a capacidade de utilizar os recursos naturais sem comprometer as gerações futuras em atender suas necessidades (NAIME, 2005).

No entanto o referido conceito contribuiu para criar um paradoxo em relação aos modelos de desenvolvimento econômico e social, da literatura clássica, que condiciona o aumento da prosperidade de uma nação e de seus cidadãos, ao poder de compra e maior taxa de consumo. A priorização do enriquecimento a qualquer custo, como condição sine qua non, para alcançar níveis mais elevados de bem estar econômico e social, passou a representar uma contradição em virtude das taxas mais elevadas de consumo de matérias primas, energia e de emissões de poluentes (SCHREIBER, 2013).

Esta preocupação com o paradoxo inovação $x$ preservação ambiental transferiu-se, gradualmente, do nível político estratégico, para o âmbito social e organizacional, estimulando a adoção de práticas organizacionais voltadas para a gestão ambiental. A gestão ambiental pode ser compreendida como o gerenciamento do exercício de atividades econômicas e sociais, de maneira a formatar o uso racional dos recursos naturais, renováveis ou não. Esta gestão é voltada 
ao desenvolvimento de métodos que garantam a conservação e a preservação da biodiversidade, a reciclagem das matérias primas e as reduções dos impactos resultantes de atividades humanas no meio ambiente (ANDRADE; TACHIZAWA; CARVALHO, 2002).

Com o objetivo geral de identificar a forma de combinar a inovação com as práticas ambientais em organizações do segmento industrial, foi realizado o estudo de caso múltiplo em três organizações, localizadas na região sul do país, por meio de abordagem qualitativa, entrevistas em profundidade e análise de narrativas, complementado com a consulta a documentos internos. A questão de pesquisa que norteou a condução do presente estudo foi: "Como organizações industriais podem combinar o processo de inovação com as práticas ambientais?".

A hipótese que procura responder a questão de pesquisa construída a partir da revisão teórica aponta como alternativa à referida combinação entre inovação e práticas ambientais, a revisão de processos organizacionais, notadamente os de natureza operacional, visando tanto um desenho inovador para a sua consecução, bem como evidenciando elementos que possam contribuir à redução do impacto ambiental.

O trabalho inicia com a apresentação das vertentes teóricas que embasaram a construção das questões que foram utilizadas no processo de entrevistas em profundidade, bem como subsidiaram a identificação das categorias analíticas. Na sequência está detalhado o método de pesquisa adotado no estudo, cujos resultados são apresentados no capítulo seguinte. O trabalho é finalizado com as considerações finais e as referências.

\section{Sistema de Gestão Ambiental}

A gestão ambiental, nas últimas décadas, tem recebido um foco maior de atenção tanto de pesquisadores como de agentes organizacionais. Isto em decorrência do potencial competitivo que a responsabilidade socioambiental pode constituir em face à crescente preocupação social (ANDRADE; TACHIZAWA; CARVALHO, 2002; DIAS, 2011).

Sendo o tema de gestão ambiental, cada vez mais recorrente, frente às organizações e, por consequência, de maior interesse de pesquisadores da área, foram elaboradas muitas definições ao tema (NAIME, 2005; DIAS, 2011; TACHIZAWA, 2011). Combinando os principais aspectos elencados pelos autores revisados, observa-se a gestão ambiental como uma atividade organizacional capaz de contribuir ao diagnóstico da situação ambiental de uma organização, bem como sustentar a proposição de um modelo de gestão, que propicie o ajuste de processos internos às determinações legais (ALIGRERI; ALIGRERI; KRUGLIANSKAS, 2009; DONAIRE, 1999; BARBIERI, 2011; MOURA, 2011).

Por compreender mudanças na estrutura e no funcionamento de organizações, destaca-se a relevância do comprometimento da alta direção na elaboração e na promoção de objetivos ambientais que irão respaldar o desenvolvimento organizacional, bem como, influenciarão a conduta de seus colaboradores. Nesse sentido, autores como Andrade, Tachizawa e Carvalho (2002) e Naime (2005) destacam que os princípios de gestão ambiental empresarial devem estar alinhados às estratégias organizacionais (BARBIERI, 2011; DIAS, 2011; MOURA, 2011; TACHIZAWA, 2011).

Pesquisas relacionadas a esta temática indicam os seguintes aspectos como relevantes a efetividade da gestão ambiental empresarial: o segmento econômico, o grau de profissionalização da gestão, o porte, o número de colaboradores e a localização geográfica do empreendimento (DONAIRE, 1999; ALIGRERI; ALIGRERI; KRUGLIANSKAS, 2009; DIAS, 2011). Nos estudos de Andrade, Tachizawa e Carvalho (2002), Naime (2005), Barbieri (2011) e Moura (2011) as motivações para o planejamento e a implantação de um programa de gestão ambiental empresarial compreendem: a possibilidade de redução de custos, a atualização tecnológica, a otimização de processos produtivos, o desenvolvimento de uma cultura interna 
ecologicamente correta, a prevenção de acidentes ecológicos, e o atendimento as demandas das partes interessadas.

A literatura revisada aponta para três estratégias de gestão ambiental: a prevenção da poluição, o planejamento do produto e o desenvolvimento sustentável. A primeira estratégia refere-se ao controle da poluição, o qual é caracterizado pela adequação normativa e atendimento às exigências de mercado (ANDRADE; TACHIZAWA; CARVALHO, 2002; NAIME, 2005). Já a segunda compreende a prevenção da poluição desde o projeto de produtos, serviços ou processos. A terceira estratégia procura estimular ações proativas e antecipatórias mediante o risco ambiental (ALIGRERI; ALIGRERI; KRUGLIANSKAS, 2009; BARBIERI, 2011; DIAS, 2011; MOURA, 2011; TACHIZAWA, 2011).

Frente à implantação de programas ambientais a literatura apresenta cinco estágios de configuração para um programa de gestão ambiental em organizações, os quais podem variar desde a ausência ou presença limitada de ações ambientais até a presença de programas difundidos por toda a organização. Podendo o estágio mais elevado incluir a educação ambiental, o monitoramento constante e a resolução rápida de problemas ambientais. Quando a temática ambiental atinge este estágio, esta passa a contribuir à elaboração de metas, políticas e estratégias organizacionais (ANDRADE; TACHIZAWA; CARVALHO, 2002; NAIME, 2005; BARBIERI, 2011; MOURA, 2011; TACHIZAWA, 2011).

Neste contexto, é possível confirmar que a adoção da prática ambiental pode estimular mudanças organizacionais. Dentre estas se destacam as práticas relacionadas aos produtos e processos. As primeiras priorizam a eliminação de elementos de potencial poluidor, a redução do consumo de recursos, o reaproveitamento e a reutilização. Já as práticas orientadas aos processos visam à conscientização ambiental produtiva e a prática preventiva e antecipatória (DONAIRE, 1999; ANDRADE; TACHIZAWA; CARVALHO, 2002; BARBIERI, 2011; MOURA, 2011).

Estudos já realizados sobre prática ambiental empresarial em organizações brasileiras evidenciam amplo leque de alternativas, concebidas e operacionalizadas, as quais variam conforme o tipo de processo ou produto, porte, segmento, localização e inovações tecnológicas adotadas (ROHRICH; CUNHA, 2004).

A implantação de um sistema de gestão ambiental deve incluir o uso de práticas que contribuam à minimização do impacto ambiental proveniente de processos produtivos, alindo o equilíbrio entre os interesses ambientais e as necessidades socioeconômicas. Neste contexto cada organização deve identificar quais os aspectos ambientais pode controlar sob o prisma de seus processos (SOLEDADE ET AL., 2007). A Figura 1 sumariza os elementos passíveis de verificação em um sistema de gerenciamento ambiental. 


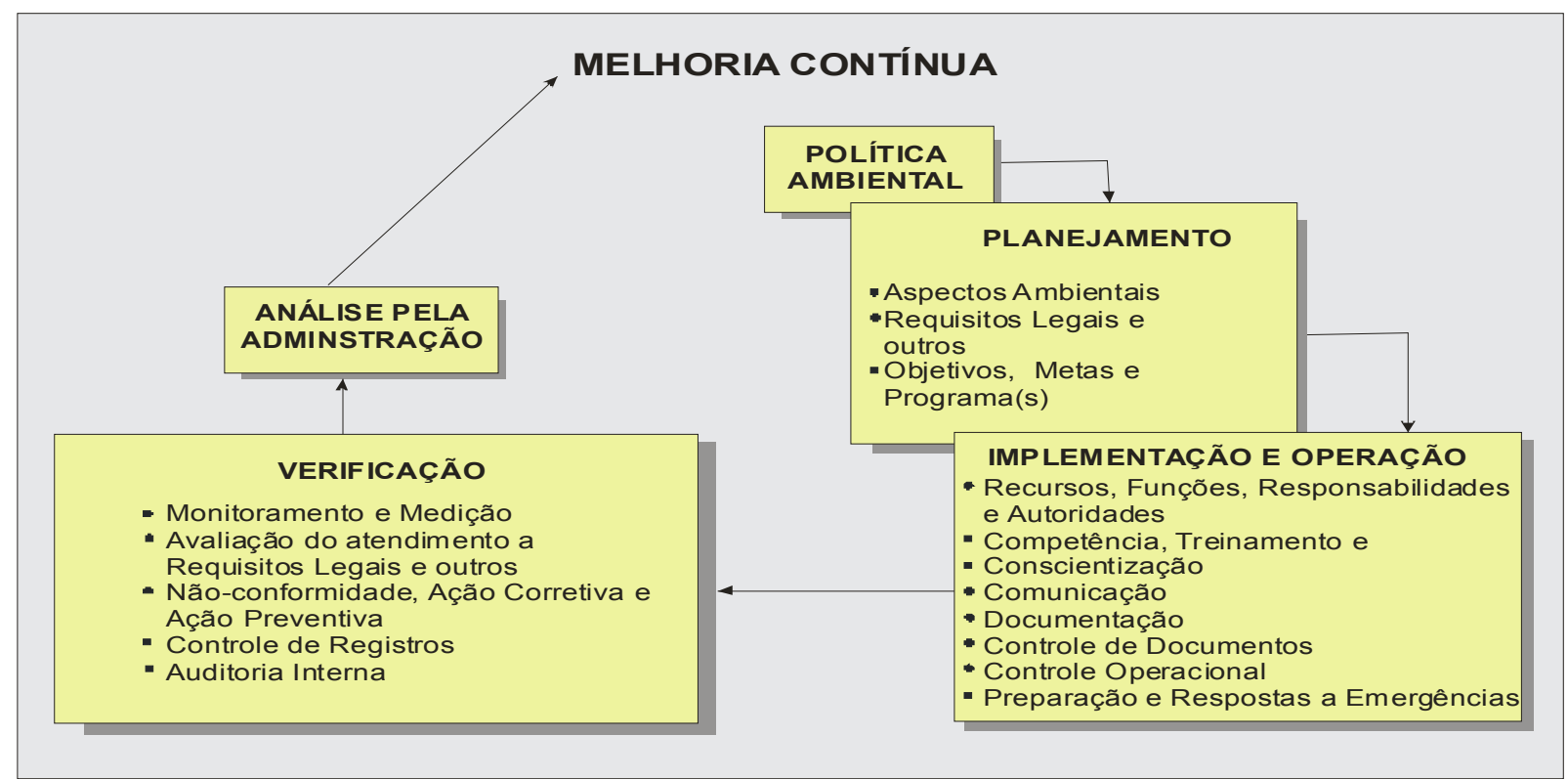

Figura 1: Elementos de um sistema de gerenciamento ambiental (SOLEDADE ET AL., 2007).

Conforme a Associação Brasileira de Normas Técnicas - NBR ISO 14001 (2004) são requisitos de um sistema da gestão ambiental: (a) Política ambiental: coerente ao negócio principal, orientada à melhoria contínua, bem como ao atendimento à legislação e normas vigentes; (b) Planejamento: baseado nos aspectos ambientais, na legislação e em outros requisitos, deve compreender objetivos, metas e programas ambientais; (c) Implantação e operação: alinhados aos recursos, comunicação, documentação, responsabilidades, autoridades, competências, treinamentos e conscientização frente à temática ambiental; (d) Verificação e ação corretiva: pertinente ao monitoramento, medição e avaliação de requisitos legais, não conformidades, ações corretivas e auditorias internas; (e) Análise pela administração: frente à adequação e a eficácia de seu sistema de gerenciamento ambiental.

Naime (2005) corrobora esta orientação ao reforçar a relevância do sistema de gestão ambiental, com vistas ao controle e à minimização dos impactos de uma atividade sobre o meio ambiente. Este autor, ainda destaca que tal sistema auxilia na definição de etapas de avaliação, de planejamento e de implantação de processos que evidenciem a orientação sustentável de uma organização. Dias (2011) e Barbieri (2011) consensam que a adoção de uma postura ambiental empresarial, assim, possui condições de contribuir a conformidade, a redução de riscos e a obtenção de vantagens econômicas competitivas.

\section{Inovação}

As mudanças na forma de produzir bens e serviços para atender às necessidades de consumo, independente de sua "real" necessidade ou percepção, sempre ocuparam papel de destaque na história mundial. Foram responsáveis, inclusive, por algumas das mudanças mais relevantes na estrutura social e política, como no modo de organizar recursos produtivos, o que influenciou a forma constitutiva na formação de custos, na definição de processos logísticos e no o acesso aos mercados de consumo (LANGLOIS, 2003).

Um dos primeiros pesquisadores a estudar a inovação no modo de agir da firma no mercado e a sua influência sobre os resultados organizacionais foi Joseph Alois Schumpeter (1982) que caracterizou a inovação como "destruição criadora". Enquanto a maioria dos teóricos e pesquisadores analisava o sistema capitalista como um problema de administração da estrutura existente, este apresentou a percepção do capitalismo como um processo de criação e destruição destas estruturas. Dentro desta proposta de análise, este autor também revisou a evolução do 
modus operandi de concorrência, verificando que, ao longo do tempo, a concorrência baseada na competição pura com base em preço, migrou para a disputa de mercados consumidores com base na qualidade do produto ou de serviços, evoluindo para uma posição de busca por diferencial competitivo.

Ao firmar tal abordagem, Schumpeter (1982) argumentou que a concorrência no sistema capitalista deve estar baseada em desenvolvimento de novos produtos, de novas técnicas, de novas fontes de suprimento e de novas formas de organização empresarial. Este tipo de concorrência é em sua opinião mais efetiva do que aquela baseada em preços, qualidade ou produção em escala.

Os estudos de Schumpeter (1982) influenciaram outros pesquisadores a se interessar pelo assunto e a orientaram o desenvolvimento de novas abordagens neste tema. Muitos destes ampliaram o conceito de inovação, aplicando-o, também, na gestão de processos organizacionais. Desta forma é facultada a reflexão sobre novas formas de organizar os recursos e orientar decisões à luz da complexidade presente, tanto no ambiente externo como no ambiente interno. Percebe-se que a competência em organizar recursos de forma inovadora e tomar decisões com vistas à otimização e aproveitamento de oportunidades prospectadas no mercado constitui a base de diferencial competitivo (WERNERFELT, 1984; VOLPE; BIFERALI, 2008).

Em seus estudos Rodney (2000) elenca três categorias de inovação (a) a gestão estratégica inovativa para o enfrentamento de mudanças ambientais, (b) a gestão de iniciativas de mudança de caráter inovador e (c) a inovação através da criação e da aplicação do conhecimento. Dentro destas categorias a inovação é segmentada na literatura tradicional em incremental e disruptiva, sendo que o mesmo autor propõe mais uma categoria: a inovação relacionada ao conhecimento. Esta decorrente do entendimento de que a construção do conhecimento inclui a criação e o reconhecimento do conhecimento que é socialmente construído. De modo que as organizações são inovadoras quando permitem que os novos conhecimentos sejam reconhecidos e aplicados, tanto em processos como em produtos.

No entanto, nem sempre é necessária a inovação radical para propiciar condições favoráveis à construção de diferencial competitivo. É evidente que a concepção de um produto com características radicalmente diferentes, às dos concorrentes possibilita a constituição de um diferencial competitivo relevante, mas esta não é uma condição possível a todos os segmentos econômicos e a custos viáveis e factíveis. Por esse motivo pequenos avanços tecnológicos tendem a ser considerados representativos e relevantes.

A relevância da inovação para o alcance de níveis superiores de retorno econômico e financeiro foi proposta por Cham (2005) em sua metáfora do oceano azul. Nesta interpretação o mercado é segmentado em dois tipos: azul ou vermelho. O oceano azul designa o segmento de atuação onde as organizações inovadoras constituem uma reserva de mercado, com base na sua competência em desenvolver "o novo", diferentemente do oceano vermelho, onde inúmeras empresas competem comercializando produtos tradicionais. Enquanto que no oceano azul as organizações prosperam, sem se preocupar com a concorrência, as empresas que operam no oceano vermelho utilizam expedientes já conhecidos da concorrência como o corte de preços e redução de custos, além de outras técnicas e métodos de gestão, transformando o mercado num verdadeiro campo de batalha, com poucos sobreviventes.

A preocupação das organizações em aproveitar oportunidades de mercado, para ampliar a sua participação, também chamou atenção de Christensen (2002) que sustentou o crescimento organizacional fundamentado em inovação. Este inicia sua abordagem na distinção entre dois tipos de circunstâncias promotoras do crescimento via inovações: as circunstâncias sustentadoras e as disruptivas.

Nas circunstâncias sustentadoras - quando a concorrência ocorre via melhoria de produtos com maior margem voltados aos clientes do topo da pirâmide - as empresas titulares quase sempre levam vantagem, mesmo que essas possuam menos recursos do que os novos entrantes. 
Por outro lado, nas circunstâncias disruptivas - quando a concorrência se dá na comercialização de produtos mais simples e acessíveis a clientes menos atrativos - as empresas entrantes é que tem sido vencedoras. Neste contexto a uma inovação disruptiva é aquela que rompe e redefine os modelos vigentes, lançando produtos e serviços de qualidade inferior aos já existentes, porém, dotados de outros benefícios (SCHREIBER; PINHEIRO, 2009).

Neste sentido, Chaharbaghi e Newman (1996) apresentaram contribuições relevantes ao constatar que o termo inovação é também empregado para descrever o processo de mudança, além de avaliar a repercussão da adoção de novos procedimentos ou produtos no indivíduo. Destarte, a inovação passa a compreender o repertório cognitivo e comportamental do mesmo. Como também pode constituir uma ideia já existente ou é vista como nova independente de sua adoção. Autores também classificam a inovação, com base em seu foco, em quatro tipos: a) no produto ou no serviço; b) no processo de produção; c) na estrutura organizacional e d) nas pessoas.

É importante, porém, destacar que a realidade sempre pode confrontar a teoria com derivações do modelo pré-concebido. Até mesmo com base em processo de reflexão sobre o tema inovação é possível inferir que a tipologia apresentada por Chaharbaghi e Newman (1996) pode ser acrescida de variações decorrentes da combinação dos tipos citados. Além disto, é relevante o estudo do timing de implementação da referida tipologia; por onde a introdução da inovação como prática organizacional, deve iniciar.

Neste ponto é imprescindível relacionar as contribuições de Christopher Freeman (1989) que em seus estudos identificou seis tipos distintos de organizações, com base em estratégias orientadas à inovação tecnológica. São eles: ofensiva (que buscam a liderança, baseada na excelência de produtos, sendo agressiva em atuação no mercado); defensiva (que prefere ser a segunda, imitando a concorrência com pequenas adaptações); imitativa (que apenas copia às vezes, integralmente sua concorrência); dependente (cujos clientes ou fornecedores são exclusivos); oportunista (que atua com base em nichos de mercado) e tradicional (cuja atuação prescinde de inovação tecnológica).

De forma complementar Tidd, Bessant e Pavitt (2005) apresentam conceitos que agregam aos dois tipos de inovação básicos (de produto e processo) a inovação de posicionamento. Esta consiste em mudanças no contexto em que os produtos e serviços estão inseridos, e a inovação paradigmática que compreende mudanças nos modelos mentais subjacentes que delimitam as ações organizacionais. No entanto, estes autores não desprezam o grau de alteração que resulta na configuração do produto final, representada pelo binômio da inovação que caracteriza a inovação incremental e inovação radical ou disruptiva.

Para Christensen (2002), a gestão da inovação relaciona elementos como marketing e produção. Ainda destaca que uma organização ao pretender o êxito na condução de um processo de inovação deve alinhar suas atividades e contemplar esta prioridade na sua estratégia organizacional. Destarte, a gestão da inovação se refere ao contexto estratégico e organizacional dos processos individuais de inovação com o objetivo de produzir produtos bem sucedidos no mercado e processos inovadores de racionalização de tempo e de recursos.

Nesse sentido, Miller e Morris (1998) aprofundam a reflexão sobre modelos de negócios baseados em inovação e identificaram três dimensões teóricas nas quais os mesmos se estruturam, a saber: economia, aprendizagem e gestão. A primeira caracteriza-se pela mudança da economia industrial para a economia do conhecimento. A segunda, por sua vez, compreende o processo de criação de conhecimento e a geração de inovações. E, por fim, a terceira dimensão que define as estruturas organizacionais e os meios pelos quais a inovação e as demais atividades de uma organização são realizadas.

Esta e outras abordagens sobre o tema inovação suscitam questões que continuam sendo objeto de debate entre pesquisadores e empreendedores. Existe, efetivamente, um padrão ideal 
para a concepção de inovação? O ato de inovar resulta de um modelo de análise estruturada ou desestruturada? Como a pesquisa científica pode contribuir ao processo de inovação?

Neste ponto, vale à pena, retomar o período histórico que serviu de cenário às primeiras concepções de inovação, pois foi o próprio Schumpeter (1982) que desenvolveu a tipologia que permitiu a identificação de cinco tipos de inovação: novos produtos ou mudanças substanciais em produtos existentes; novos processos ou métodos de produção; novos mercados, novas fontes de recursos e novas organizações. De maneira que este tema supera questões tecnológicas, este inclui vários outros setores organizacionais.

Dificilmente a inovação tecnológica vem desacompanhada da inovação organizacional, que é considerada essencial e subjacente à constituição de um ambiente propício ao ato de inovar. Segundo o Manual de Oslo, publicado pela Organização para a Cooperação e Desenvolvimento Econômico - OCDE (2006), a inovação tecnológica, presente nas organizações, manifesta-se através da mudança em produtos e processos. Vários produtos inovadores requerem mudanças em processos para serem levados ao mercado.

Um produto, para ser considerado tecnologicamente novo, demanda inovações que envolvam mudanças conceituais radicalmente inéditas, baseadas na combinação de tecnologias já existentes ou derivadas do uso de um novo conhecimento. A inovação também pode ser compreendida como a formulação, a combinação ou a síntese do conhecimento em novos produtos, processos ou serviços. Inovações em processos podem revolucionar uma indústria, diminuindo custos, reduzindo etapas produtivas e acrescentando novas formas de serviços (CHRISTENSEN, 2002).

\section{Método e procedimentos de pesquisa}

O método de pesquisa escolhido foi o estudo de caso, por se entender que apresenta melhor aderência ao objetivo e às questões que nortearam o presente estudo. Tull e Hawkins (1976, p. 323) afirmam que "um estudo de caso refere-se a uma análise intensiva de uma situação particular". De acordo com Yin (2005), a preferência pelo uso do estudo de caso deve compreender o estudo de eventos contemporâneos, em situações onde os comportamentos relevantes não possam ser manipulados, mas onde seja possível observar diretamente e realizar entrevistas sistemáticas. $O$ presente estudo foi realizado com uma visão externa dos pesquisadores, sem envolvimento nem manipulação de quaisquer informações e os fatos levantados pelo estudo são contemporâneos. Dentre as aplicações para o estudo de caso citado por Yin (2005), nesse trabalho procurou-se descrever o contexto da vida real e realizar uma avaliação descritiva.

O estudo de caso é útil, segundo Bonoma (1985, p. 207), "... quando um fenômeno é amplo e complexo, onde o corpo de conhecimentos existente é insuficiente para permitir a proposição de questões causais e quando um fenômeno não pode ser estudado fora do contexto no qual ele naturalmente ocorre". Este autor, ainda destaca que os objetivos do método do estudo de caso não são a quantificação ou a enumeração, mas a descrição, a classificação (desenvolvimento de tipologia), o desenvolvimento teórico, e o teste limitado da teoria, de modo geral o objetivo é a compreensão. $\mathrm{Na}$ parte empírica deste estudo descrevem-se situações que ocorreram, confrontando-as com a teoria de forma restrita às organizações pesquisadas.

Esta descrição baseia-se na análise de narrativas, construídas a partir das entrevistas não estruturadas realizadas nas organizações pesquisadas, com as pessoas que trabalham na área de P\&D e gestão ambiental. Após a sua transcrição, as entrevistas, que, devido ao seu formato, resultaram, normalmente, em um texto não linear e até confuso, são interpretadas e reescritas na forma de um texto coeso, fluido, na primeira pessoa, em formato de narrativa. Na sequência estes foram submetidos à apreciação dos entrevistados, para conferência, ajustes ou contribuições. 
Apesar do método não ser considerado recente, ainda é tratado como inovador (BOJE, 1995; MOEN, 2006).

A narrativa pode ser interpretada como uma fala organizada acerca de um determinado evento, situação, assunto ou tema. De modo mais detalhado, compreende a forma pela qual as pessoas contam suas experiências, o que elas enfatizam ou omitem, se elas se posicionam como protagonistas ou como vítimas. É importante destacar que o relacionamento que o narrador estabelece com o ouvinte faz com que a narrativa deixe de ser apenas o ato de contar algo, mas passe a ser um ato de construção de uma identidade pessoal (POLKINGHORNE, 2007). A narrativa faz parte do processo cultural onde os sistemas simbólicos criam e são criados através, do discurso e é empregada em diferentes contextos para comunicar diferentes pontos de vista. Fragmentos de narrativas maiores e versões diferentes de narrativas fazem parte do discurso cotidiano das pessoas, que são, afinal de contas, seres constituídos na linguagem baseada em significados construídos para dar sentido ao mundo em que vivem. São estes significados que fazem parte da rede de conversações, constituindo o conjunto de valores, de símbolos, representações, enfim, a cultura à qual acabam se integrando (BOJE, 1995; MOEN, 2006).

Segundo Czarniawska (2001) o método de análise de narrativas julga-se adequado para desvelar ao pesquisador os processos adotados pelo narrador para interpretar coisas, particularmente indicado para avaliar a interpretação do indivíduo frente a temas subjetivos. Cabe ao pesquisador interpretar as impressões do narrador. No entanto é importante destacar que o pesquisador não possui acesso direto à experiência do outro e por esse motivo este trata e sempre tratará com formas diferentes e ambíguas de representação da experiência que o outro relatará por meio de fala, texto, interação e, é claro, pela interpretação. Por essa razão torna-se impossível ao pesquisador manter-se neutro ou objetivo na representação da realidade.

A questão de pesquisa que orientou o desenvolvimento deste estudo foi: "Como organizações industriais podem combinar o processo de inovação com as práticas ambientais?". Em alinhamento com a questão de pesquisa e opção metodológica os pesquisadores fizeram uso de uma abordagem qualitativa, utilizando perguntas abertas para a coleta de dados. Foram elaboradas apenas cinco perguntas, construídas a partir da revisão teórica sobre os temas inovação e gestão ambiental, a saber: (a) como ocorre o processo de inovação na empresa?; (b) quais são as inovações adotadas pela organização e que você considera como mais relevantes?; (c) quais são as práticas ambientais adotadas e operacionalizadas pela organização?; (d) quais foram as principais dificuldades no processo de operacionalização das práticas ambientais?; (e) como, na sua percepção, é possível conciliar a necessidade de inovar com a de atender às exigências legais da gestão ambiental?.

Para a realização da pesquisa foram escolhidas três organizações industriais, com base no critério de relevância regional dentro da matriz produtiva local, acessibilidade e conveniência. Em cada uma das organizações foram entrevistados apenas gestores de pesquisa e desenvolvimento e gestão ambiental. Pela exigência das organizações de manter o anonimato, as mesmas serão denominadas de ALFA, BETA e GAMA.

Com o objetivo de contextualizar as evidências que emergiram ao longo das narrativas realizadas com os gestores das três organizações, se faz mister a descrição sumária de cada uma delas. Esta é uma recomendação metodológica inerente à opção metodológica qualitativa, que faz uso de entrevistas em profundidade e análise de narrativas, conforme indicado por autores como RIESSMAN (1993), BOJE (1995) e CZARNIAWSKA (2001).

\section{Análise dos resultados}

Para preservar a identidade das mesmas, exigência condicionada à autorização para a coleta de dados e participação da pesquisa, as três indústrias foram nomeadas como empresa ALFA, BETA e GAMA. 
A empresa ALFA foi constituída em 1996 e atua na fabricação de plásticos especiais para o segmento automobilístico, alimentício, aeronáutico, civil e aplicações especiais como tecnologia aeroespacial, comunicação, médica e movimentação de cargas. Atualmente a empresa conta com 100 colaboradores e um volume de produção de 300 ton/mês. A inovação de produto e de processos é considerada pela direção uma obrigação institucional, em virtude do tipo de produto e o foco no atendimento às demandas de mercado. Além disso, a empresa possui certificação ISO 9001 desde o ano de 2000. A partir de 2006 a organização também optou por adotar as práticas ambientais baseadas na legislação e nas normas vigentes, de modo a atender às solicitações de determinados clientes e a estar mais alinhada às práticas ambientalmente responsáveis, objetivando assim, manter os clientes atuais e a prospectar novos mercados.

A empresa BETA foi fundada em 1994 para fabricar e comercializar laminados e sintéticos para a indústria calçadista e de material esportivo. Atualmente é uma referência junto às grandes marcas nacionais e internacionais, em virtude de soluções inovadoras, tanto em nível de produtos, bem como atendimento customizado às demandas de clientes. A empresa conta com 86 colaboradores e um parque fabril de 4.603,12 metros quadrados. A empresa criou uma área de Gestão Ambiental no ano 2007, a qual está posicionada como staff da presidência, não se subordinando às diretorias industrial e comercial, o que faculta a concepção e a implementação de políticas organizacionais que priorizam a gestão ambiental.

A GAMA iniciou sua operação na década de sessenta do século passado, no estado de Santa Catarina, através da fabricação de chapéus de praia e campo, mas cinco anos depois reorientou sua operação para fabricação de malhas. Na década de noventa ingressa no segmento de fabricação de calçados, constituindo uma unidade no estado vizinho, Rio Grande do Sul, resultando da aquisição de duas fábricas de calçados infantis que operavam em Novo Hamburgo. A empresa instituiu oficialmente o programa de inovação no ano 2007, quando a direção da empresa contratou uma consultoria para apoiar o desenho institucional, que pudesse facultar o referido processo. Já a preocupação ambiental acompanhou a gestão da unidade, desde a sua constituição, em virtude do volume de resíduos gerados e seu alto impacto ambiental. Apesar desta preocupação inexiste na empresa um programa específico e tampouco um setor encarregado de coordenar as atividades de gestão ambiental.

Nas três organizações os gestores entrevistados foram indicados pela direção, todos responsáveis pelas áreas de produção, desenvolvimento de novos produtos e gestão ambiental. Com o propósito de proceder à coleta de dados, informações e evidências que pudessem facultar a compreensão do processo de inovação e das práticas de gestão ambiental, para estudar as possibilidades de combinação de ambos, nas três organizações, foram realizadas entrevistas em profundidade, com reduzido número de questões. Desta forma foi facultado aos entrevistados manifestar-se de forma mais livre acerca dos temas abordados, realizando comentários irrestritos sobre os processos organizacionais, a inovação e as práticas de gestão ambiental.

Considerando a posição hierárquica ocupada pelos entrevistados, é possível afirmar que a percepção dos mesmos, acerca do universo organizacional, é relevante e significativa, por representarem, tanto formal como informalmente, a organização, no âmbito interno e externo, formando e influenciando os demais colaboradores. Desta forma a visão, a percepção e a interpretação de fatos e dados dos fenômenos organizacionais, manifestada pelos entrevistados, podem ser consideradas suficientes para a coleta de indícios acerca dos temas abordados no âmbito do presente estudo (RIESSMAN, 1993; BOJE, 1995; CZARNIAWSKA, 2001; MOEN, 2006).

A análise de narrativas, realizada a partir das entrevistas em profundidade, facultou a identificação de especificidades que evidenciam a combinação de inovação de processos com as práticas ambientais. A caracterização e consequente análise de inovação de processos seguiram a literatura revisada sobre o tema (RODNEY, 2000; CHRISTENSEN, 2002; TIDD; BESSANT; PAVITT, 2005; CHAM, 2005). Já os quesitos que tipificam as práticas de gestão ambiental 
referem-se ao arcabouço legal, instituído pela Norma NBR ISO 14001:2004, conforme indicado por Aligleri, Aligleri e Kruglianskas (2009), Barbieri (2011), Dias (2011) e Moura (2011).

Inicialmente os entrevistados foram solicitados a comentar a respeito do processo organizacional voltado para o estabelecimento de uma política ambiental, conforme exigido pela norma ISO 14001:2004 (MOURA, 2011; BARBIERI, 2011) e sobre a relevância da inovação para a organização, que para Tidd, Bessant e Pavitt (2005) deve ocupar papel de destaque nas estratégias organizacionais.

Divergindo da forma tradicional de concepção de políticas, que ainda existem em curso em muitas organizações (DONAIRE, 1999; NAIME, 2005), e de sua definição observando apenas as peculiaridades da sua própria estrutura organizacional, a ALFA realizou benchmark com empresas líderes do setor. A BETA revisou suas políticas, contemplando a preocupação ambiental e inovação em sua nova versão e a GAMA também inovou o processo de concepção de políticas, ao acolher contribuições de seus clientes intermediários, de varejo de calçados, o que evidenciou a necessidade de observar as tendências de mercado, como, por exemplo, a operacionalização do Sistema de Gestão Ambiental - SGA.

Os processos subjacentes ao planejamento, a implantação e operacionalização de um SGA seguiram o padrão estabelecido no primeiro tópico abordado, mantendo a coerência e nexo lógico. Na empresa ALFA optou-se pelo empoderamento de um grupo misto de colaboradores, representantes da maioria das unidades organizacionais, para coordenar o processo de inovação e de SGA. Na BETA a empresa de consultoria auxiliou na seleção de um coordenador do programa SGA, que criou um blog na internet, com ouvidoria virtual e sugestões para o programa, sendo que o grupo de colaboradores, a quem foi atribuída a tarefa de captar sugestões de inovação, passou a interagir e a avaliar as propostas com base em critérios estabelecidos pela ISO 14001:2004. Já na GAMA o setor de controladoria, encarregado de analisar as propostas de inovação de processos e tecnológica, por meio de investimentos em novas máquinas e equipamentos, desenvolveu um módulo no ERP, para planejar o SGA e acompanhar sua evolução no âmbito organizacional.

Foi possível constatar também inovações de processos para prover capacitações de colaboradores no âmbito do SGA. Na ALFA foram adquiridas publicações sobre o tema de gestão ambiental, bem como custeadas participações de colaboradores em seminários, encontros e congressos externos. Estes colaboradores passaram a atuar como multiplicadores, promovendo capacitações internas, por meio de workshops e reuniões. Na BETA, com apoio da consultoria contratada, foram criados espaços de reflexão e seminários mensais, com o intuito de compartilhar as boas práticas, tanto em inovação como em gestão ambiental. Já na GAMA foram contratados especialistas para a capacitação de líderes, que assumiram a responsabilidade de coordenar os trabalhos de inovação e de gestão ambiental em seus respectivos setores.

A concepção de práticas colaborativas intra e interorganizacionais com o objetivo de promover a aprendizagem e a gestão do conhecimento, subsidiando as alterações de processos e práticas organizacionais, conforme evidenciado nas empresas ALFA e BETA representa a inovação de processos, segundo a literatura revisada (CHAHARBAGHI; NEWMAN, 1996; CHRISTENSEN, 2002). A inovação de processos também se reflete em estruturas matriciais e de equipes mistas, que propiciam formas mais eficazes de compartilhamento de experiências, vivências e percepções, oportunizando a realização de mudanças estruturantes de práticas organizacionais constituídas. Da mesma forma é possível afirmar que a combinação de tecnologias de informações, tais como intranet, páginas na internet e sistemas de gestão (ERP) representam opções criativas, de caráter inovador, para respaldar a implantação de SGA, no caso da empresa GAMA.

A combinação similar de práticas ambientais com as práticas de inovar foi encontrada também no monitoramento e na ação corretiva, que, segundo Moura (2011) e Dias (2011) consistem no monitoramento e medição, na identificação de não conformidades e na concepção de ações 
corretivas, na realização de registros sistemáticos e, também, de auditorias de SGA. Na empresa ALFA destaca-se a constituição de uma comunidade de prática de colaboradores, com espaço virtual para comunicação, através da intranet, onde são "depositadas" as contribuições de envolvidos no processo de controle de SGA, em termos de compartilhamento de experiências, avisos, lembretes, que reduzem o tempo despendido nesta atividade. Também são postados os relatos de ações corretivas realizadas e o grau de sua efetividade. O ineditismo destas ações, configurando assim a inovação organizacional, é confirmada pelas características destacadas na literatura revisada sobre o tema inovação (CHAHARBAGHI; NEWMAN, 1996; MILLER; MORRIS, 1998; CHAM, 2005).

Na BETA a empresa de consultoria auxiliou na concepção de rotinas internas, com o intuito de facultar esta etapa do SGA, além de colocar à disposição da equipe interna da BETA o aplicativo, com base de dados na nuvem e gerenciada pela consultoria, que permitiu acompanhamento em tempo real, bem como facultou sua instalação em unidades móveis, como tablets e smartphones, pelos componentes da equipe de gestão. Uma das interfaces do aplicativo facultava mensurar o impacto ambiental a partir de sugestões de mudanças/ inovação de processos internos, em especial, dos de natureza operacional. Além disso, como também foi evidenciado na GAMA, o aplicativo oferecia a construção de tabela de indicadores ambientais, comparativo do previsto e do realizado, além de padrões de planos de ação corretiva e telas para dar suporte às auditorias de SGA. A adoção destas tecnologias representa a inovação de processo, que foi combinada com os objetivos de adotar as práticas ambientais, conforme tipificado por autores como Christensen (2002) e Tidd, Bessant e Pavitt (2005).

No tocante à etapa de gerenciamento ambiental, que consiste na realização de análise de resultados decorrentes de auditoria ambiental, bem como em circunstâncias de mudanças (na legislação, nos produtos ou atividades da organização, avanços tecnológicos, entre outros) também se verificou nas três organizações estudadas evidências de combinação de inovação com as práticas ambientais. Dentre as mais relevantes destacaram-se a reconfiguração de processos produtivos, de linha para célula de produção, resultando em redução de resíduos sólidos, nas empresas ALFA e BETA, e a introdução de técnicas de produção enxuta na GAMA, que implicou na troca de fornecedores, com opção por aqueles localizados mais próximos da planta de produção, além de reduzir os estoques de insumos e matérias primas.

Na melhoria contínua, última das etapas previstas pela ISO 14001:2004, constatou-se, a partir da narrativa dos entrevistados das três organizações, que está prevista a utilização da mesma estrutura organizacional que foi definida para a gestão, tanto dos processos de inovação, como de gestão ambiental. Desta forma a direção entende que será possível promover a interação interna, entre os setores e programas, para que, de forma simultânea, possam avançar rumo ao aperfeiçoamento tanto das técnicas como ferramentas e métodos empregados para a operacionalização de gestão ambiental e da inovação de processos, em vista da centralidade de ambos para prover a competitividade das organizações.

\section{Considerações Finais}

Nas últimas três décadas a inovação assumiu um papel de destaque nas organizações, por oportunizar a migração da competição com base em custo, para a diferenciação, facultando a operação com margens de retorno acima das médias praticadas no mercado. Trata-se do "merecido" retorno extraordinário aos empreendedores inovadores de Schumpeter (1982).

No entanto o paradigma do desenvolvimento econômico a todo custo foi colocado em debate, na segunda metade do século passado, com base nas evidências de acelerada deterioração do meio ambiente, em virtude do aumento substancial de geração e do descarte inapropriado de resíduos. O crescimento econômico e social, fundamentado em consumo desenfreado, passou a ser questionado. 
Destarte surgiu o desafio de como conciliar os interesses econômicos e sociais e, de forma mais específica, em nível das organizações, como lidar com a necessidade de promover as inovações, para constituir o diferencial competitivo, sem impactar o meio ambiente. Dois temas aparentemente antagônicos e controversos representam o desafio relevante não apenas para os gestores organizacionais, mas também para o governo e a academia, em especial da área de conhecimento de ciências sociais aplicadas, em virtude de seu compromisso em contribuir para o aperfeiçoamento da gestão organizacional.

Com o propósito de contribuir para o referido debate foi conduzida a pesquisa, nos moldes de estudo de caso múltiplo, em três organizações industriais, localizadas na região sul do Brasil, utilizando a abordagem qualitativa e coleta de evidências através de entrevistas em profundidade com os gestores indicados pela direção de cada uma das empresas pesquisadas. A análise de narrativas facultou a identificação de alternativas de convergência de iniciativas de inovar processos internos com as práticas ambientais, nos moldes tipificados na literatura que versa sobre os temas inovação e gestão ambiental (CHAHARBAGHI; NEWMAN, 1996; MILLER; MORRIS, 1998; DONAIRE, 1999; CHAM, 2005; ALIGRERI; ALIGRERI; KRUGLIANSKAS, 2009; BARBIERI, 2011; MOURA, 2011).

As categorias de análise ambiental, que respaldaram o estudo basearam-se nas recomendações da norma ISO 14001:2004, e as utilizadas para averiguar o grau de inovação em processos organizacionais foram fundamentadas na revisão teórica sobre o tema, com contribuição de diversos autores, com destaque para Tidd, Bessant e Pavitt (2005).

A análise cruzada das categorias pré-definidas possibilitou a caracterização de inovação de processos em cada uma das etapas de gestão ambiental, a saber, (a) concepção de políticas institucionais com foco no SGA; (b) planejamento da implantação do sistema de gestão ambiental; (c) implementação e operação; (d) verificação; (e) análise pela alta administração e (6) melhoria contínua.

Os resultados do estudo evidenciaram as possibilidades e as restrições no processo de concepção de soluções de inovação de produtos e em processos internos, dentro dos limites técnicos impostos pela legislação concernente à gestão ambiental. Também foi possível constatar que a forma adotada pelas organizações de inovar os processos em combinação com as práticas ambientais depende do posicionamento estratégico, da estrutura interna e dos recursos disponíveis para investimento, bem como as prioridades percebidas pela alta gestão. Apesar das limitações para a obtenção de dados acerca das organizações, em virtude do caráter sigiloso da maioria das informações acessadas, pode-se concluir que o tema abordado é relevante, não apenas para as empresas estudadas, mas para todas do segmento industrial que ainda se deparam com o desafio, e a necessidade, de aliar inovação e prática ambiental em suas operações.

\section{Referências}

ALIGLERI, Lílian M; ALIGLERI, Luiz Antonio; KRUGLIANSKAS, Isak. Gestão socioambiental: responsabilidade e sustentabilidade do negócio. São Paulo, SP: Atlas, 2009. xV, 242 p. ISBN 9788522455058.

ANDRADE, Rui Otávio Bernardes de; TACHIZAWA, Takeshy; CARVALHO, Ana Barreiros de. Gestão ambiental: enfoque estratégico aplicado ao desenvolvimento sustentável. 2. ed. São Paulo, SP: Pearson Education do Brasil, 2002. xvi, 232 p. ISBN 8534611084.

ASSOCIAÇÃO BRASILEIRA DE NORMAS TÉCNICAS. NBR ISO 14001: sistemas da gestão ambiental: requisitos com orientações para uso. Rio de Janeiro: ABNT, dezembro 2004.

BARBIERI, José Carlos. Gestão ambiental empresarial: conceitos, modelos e instrumentos. 3. ed., atual. e ampl. São Paulo, SP: Saraiva, 2011. xviii, 358 p. ISBN 9788502141650. 
BOJE, David M. Stories of the storytelling organization: A postmodern analysis of Disney as

“Tamara-Land". Academy of Management Journal, August 1995, v. 35, p. 997-1035.

BONOMA, T. V. Case research in marketing: opportunities, problems, and process. Journal of Marketing Research, v.22, n.2, p.199-208, 1985.

CHAHARBAGHI; Kazem; NEWMAN, Victor. Innovating: towards an integrated learning model. Management Decision. London: 1996. Vol. 34; Num. 4; pg. 5-13.

CHAM, Kim W. A estratégia do Oceano Azul - como criar novos mercados e tornar a concorrência irrelevante. $5^{\text {a }}$ Ed. Rio de Janeiro: Elsevier, 2005.

CHRISTENSEN, Jens Froslev. Corporate strategy and the management of innovation and technology. Industrial and Corporate Change, 2002. Volume 11, Number 2, pgs. 263-288.

CZARNIAWSKA, Barbara. Anthropology and Organizational Learning, cap. 5, p. 118-136. Do Handbook: DIERKES, Meinolf; ANTAL Ariane. B.; CHILD, John; NONAKA, Ikujiro (Orgs.). Organizational Learning and Knowledge, New York: Oxford, 2001.

DIAS, Reinaldo. Gestão ambiental: responsabilidade social e sustentabilidade. 2. ed., rev. e atual. São Paulo, SP: Atlas, 2011. x, 220 p. ISBN 9788522462865

DONAIRE, Denis. Gestão ambiental na empresa. 2. ed. São Paulo, SP: Atlas, 1999. 169 p. ISBN 8522421854

FREEMAN, Christopher. The economics of industrial innovation. Cambridge: The MIT Press, 1989.

LANGLOIS, Richard N. The vanishing hand: the changing dynamics of industrial capitalism. Industrial and Corporate Change, v.12, n.2, p.351-885, 2003.

MILLER, William L.; MORRIS, Langdin. 4th Generation R\&D: Managing Knowledge, Technology, and Innovation. Nova Iorque, John Wiley \& Sons, Inc., 1998.

MOEN, Torill. Reflections on the Narrative Research Approach. International Journal of Qualitative Methods. c5 (4) December 2006.

MOURA, Luiz Antônio Abdalla de. Qualidade e gestão ambiental: sustentabilidade e ISO 14.001. 6. ed. Belo Horizonte, MG: Del Rey, 2011. xiv, 418 p. ISBN 9788538401766

NAIME, Roberto Harb. Diagnóstico ambiental e sistemas de gestão ambiental: incluindo a atualização da série ISO 9000 e as novas NBR 14001/2004 e NBR ISO 19011 / 2002. Novo Hamburgo, RS: Feevale, 2005. 164 p. ISBN 8586661813

OCDE-FINEP. Manual de Oslo. Rio de Janeiro, 2006. Disponível em: http://download.finep.gov.br/imprensa/manual_de_oslo.pdf.

POLKINGHORNE, Donald e. Validity issues in narrative research. Qualitative Inquiry, v.13, n.4, p.471-486, 2007.

RIESSMAN, Catherine Kohler. Narrative analysis. London: SAGE, 1993. 
RODNEY, McAdam. Knowledge management as a catalyst for innovation within organizations: a qualitative study. Knowledge and Process Management; Oct/ Dec 2000; 7, 4; pg. 233.

ROHRICH, Sandra Simm; CUNHA, João Carlos da. A Proposição de uma Taxonomia para Análise da Gestão Ambiental no Brasil. RAC, v. 8, n. 4, 2004: p. 81-87.

SCHREIBER, Dusan; PINHEIRO, Ivan. Gestão da inovação e o processo de alinhamento estratégico da subsidiária brasileira: caso da empresa Alfa. In: XXIX Encontro Nacional de Engenharia de Produção. Bahia: ENEGEP, 2009.

SCHREIBER, Dusan. Análise do processo de inovação com as práticas ambientais. In: VX Congresso Latino-Iberoamericana de Gestão de Tecnologia. Porto: ALTEC, 2013. Disponível em: http://www.altec2013.org/programme_pdf/218.pdf. Acesso em: 10 mar 2015.

SCHUMPETER, Joseph A. Teoria do desenvolvimento econômico: uma investigação sobre lucros, capital, crédito, juro e o ciclo econômico. São Paulo: Abril Cultural, 1982.

SOLEDADE, M. G. M.; FILHO, L. A. F. K. N.; SANTOS, J. N.; MAC-ALLISTER, M. A. ISO 14000 e a gestão ambiental: uma reflexão das práticas ambientais corporativas. In: Encontro nacional sobre gestão empresarial e meio ambiente, 9, Curitiba. Anais ... Curitiba: ENGEMA, 2007.

TACHIZAWA, Takeshy. Gestão ambiental e responsabilidade social corporativa: estratégias de negócios focadas na realidade brasileira. 7. ed. São Paulo, SP: Atlas, 2011. xvii, 450 p. ISBN 9788522462452

TIDD, J.; BESSANT, J.; PAVITT, K. Managing innovation: integrating technological, market and organizational change. 3. ed. Chichester: John Wiley \& Sons, Ltd, 2005.

TULL, D. S. \& HAWKINS, D. I. Marketing Research, Meaning, Measurement and Method. Macmillan Publishing Co., Inc., London, 1976

VOLPE, Loredana; BIFERALI, Daniele. Edith Tilton Penrose, The Theory of the Growth of the Firm, John Wiley \& Sons, New York, 1959. Springer Science+Business Media, LLC. 2008, V. $12, \mathrm{~N}^{\mathrm{o}} 1$, p. 119-125.

WERNERFELT, B. A resource-based view of the firm. Strategic Management Journal, v.5, n.2, p. 171-180, 1984.

YIN, Robert. Estudo de caso: planejamento e métodos. Porto Alegre: Bookman, 2005. 